\title{
Medical abbreviations: writing little and communicating less
}

Kathleen E Walsh and Jerry H Gurwitz

Arch. Dis. Child. 2008;93;816-817

doi:10.1136/adc.2008.141473

Updated information and services can be found at:

http://adc.bmj.com/cgi/content/full/93/10/816

\section{These include:}

Rapid responses

You can respond to this article at:

http://adc.bmj.com/cgi/eletter-submit/93/10/816

Email alerting Receive free email alerts when new articles cite this article - sign up in the box at service the top right corner of the article

Topic collections Articles on similar topics can be found in the following collections

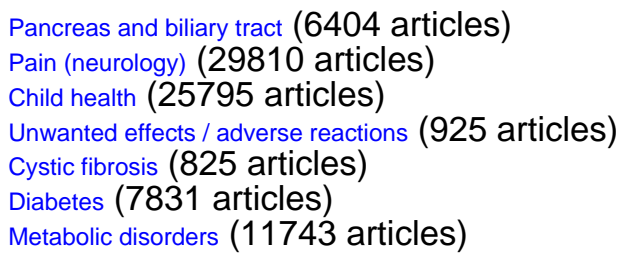

Notes

To order reprints of this article go to:

http://journals.bmj.com/cgi/reprintform

To subscribe to Archives of Disease in Childhood go to:

http:/journals.bmj.com/subscriptions/ 


\section{Medical abbreviations: writing little and communicating less}

\section{Kathleen E Walsh, ${ }^{1,2}$ Jerry H Gurwitz ${ }^{2}$}

The article by Sheppard and colleagues ${ }^{1}$ in the March issue of Archives of Diseases in Childhood describes the overuse of ambiguous abbreviations in paediatric note taking. Reading this article led one of us to review a clinic note written earlier in the day describing a "2 yo $F$ here for a RPE w/a recent URI who c/o ear pain $y / d$ ". On further inspection, this note was found to contain 35 abbreviations, all of which were completely unambiguous to the author when the note was written. However, many could certainly cause confusion should any other healthcare providers require information to make clinical decisions about this patient in the future.

Optimal communication between healthcare providers, frequently through our notes, is essential for supplying high quality care within and across clinical settings. With the involvement of greater numbers of healthcare professionals in the care of patients, and with provider responsibilities often restricted to either the hospital or ambulatory settings, substantial attention is being focused on improving handovers and transitions in medical care. Sheppard and colleagues ${ }^{1}$ have systematically detailed one important challenge to communicating written information about our patients, with serious implications. They describe the prolific use of ambiguous medical abbreviations in note keeping. In their review of 25 paediatric handover sheets and 168 sets of medical notes, the authors identified 221 and 3668 abbreviations, respectively. Paediatric physicians were able to accurately recognise $56-94 \%$ of these. However, only about half of the abbreviations were understood by other healthcare professionals, such as ancillary staff or physicians from other disciplines. While this study was conducted in a single large

\footnotetext{
${ }^{1}$ Department of Pediatrics, University of Massachusetts Medical School, Worcester, Massachusetts, USA; ${ }^{2}$ Meyers Primary Care Institute, University of Massachusetts Medical School, Fallon Clinic Foundation, and Fallon Community Health Plan, Worcester,

Massachusetts, USA
}

Correspondence to: Dr Kathleen E Walsh, Benedict Second Floor, UMass Medical Center, 55 North Lake St, Worcester, MA 01655, USA; walshk02@ummhc.org general hospital in the UK and focused solely on paediatric note keeping, the findings are certainly generalisable to other patient populations, other clinical settings and other countries.

\section{Perspective on the paper by Sheppard et a/ 1}

In addition to information exchange between healthcare professionals, providing high quality healthcare also necessitates clearly written communication from providers to patients and their families. For paediatric patients, the involvement of parents adds an added dimension to handovers. The number of available therapeutic options has increased and some children, such as those with cancer, diabetes mellitus or cystic fibrosis, are prescribed complex medication regimens. This information must be conveyed accurately each time a child transfers between the outpatient and inpatient settings, or visits a specialist in the community for a consultation and then returns to see the primary care provider. With chronically ill patients, many ancillary staff may be involved, requiring that communication flows across disciplines. Parents are often relied upon to know crucial clinical information, to understand this information and to convey this information across clinical settings and between healthcare providers. Ambiguous abbreviations only serve to confuse these exchanges and increase the chance of errors. ${ }^{2}$

Communication problems have been implicated in half of inpatient paediatric medication errors. ${ }^{3}$ According to the Institute for Safe Medication Practices, several abbreviations, when used in medication ordering, have led to misunderstandings by nurses causing dangerous and sometimes fatal medication administration errors. ${ }^{4}$ For example, a patient with diabetes whose physician ordered 6 units of insulin, written "insulin 6U", was administered 60 units by the nurse who misread the "U" as a zero. In another example, an order for a medication "Q.D." (once a day) was misread and administered "Q.I.D." (four times a day).
The use of abbreviations may hinder verbal as well as written communication. When speaking with families, physicians sometimes unintentionally slip into medical jargon, peppering their explanations and instructions with abbreviations. For example, when faced with a febrile infant, a physician trainee informed the already anxious parents that their child needed a "UA", "LP" and "CBC" as part of the "work-up" to "rule out sepsis"; use of such language will clearly confuse family members. Written abbreviations on prescriptions or consult notes, such as "SOB" for shortness of breath, may also upset families. Abbreviations used in verbal communication of medication orders, such as "mils" or "m.l.s" for milliliters or "miggs" for milligrams are similarly problematic. Abbreviations which have two possible meanings seem to be particularly troublesome for healthcare providers reading notes written by someone from another discipline. For example, "BPD" can mean bronchopulmonary dysplasia or borderline personality disorder. Presumably, the age of the patient and context may help the reader differentiate between these conditions, but should that be necessary? Lastly, the use of abbreviations to describe a circumstance or condition may evolve over time, as exemplified by the change from MR (mental retardation) to $\mathrm{DD}$ (developmental delay) to $\mathrm{CI}$ (cognitively impaired).

Given that the use of abbreviations in medicine is pervasive, what are the clinical implications of this study? The authors suggest that paediatric notes should contain only standard abbreviations. While this seems a simple recommendation, the implementation and enforcement of such a policy for the very large number of different abbreviations the authors found in paediatric notes alone would be very cumbersome. Given that there is currently no evidence to link many of these abbreviations to actual patient harm, enforcing the use of a standard list of abbreviations may not be an efficient strategy for improving patient safety and healthcare quality.

A more practical approach, that can be enforced, is the prohibition of a limited number of clearly dangerous abbreviations which have caused patient harm or which have substantial risk of causing harm. Among the 2008 National Patient Safety Goals of the U.S. Joint Commission is the implementation of a prohibited abbreviations requirement, involving a list of 15 dangerous abbreviations (such as U, Q.D., Q.I.D.) that are 
absolutely prohibited from use not only in medication orders and medication administration records but anywhere in the medical record. ${ }^{5}$ When an order is written using a prohibited abbreviation, the provider is required to rewrite the order before the medication can be dispensed by the pharmacy. Enforcing this policy requires intensive and ongoing work by institutions, including training of all medical staff, reviewing medical records to monitor compliance, and a system of feedback to offending healthcare providers.

Beyond prohibiting dangerous abbreviations, a good electronic health record may help reduce the use abbreviations in paediatric note keeping. Computerised physician order entry has been shown to reduce medication errors, in part by requiring complete orders. ${ }^{67}$ While there are concerns that the current generation of electronic health records do not always streamline written communication, ${ }^{8}$ it would be possible for an electronic health record to efficiently cue and assist the provider in replacing dangerous abbreviations with complete wording. Electronic health records which share information across systems of care, as is the goal of the National Health Service Connecting for Health, may improve communication between practitioners. ${ }^{9}$
Even in a paper based system, some simple steps may help reduce ambiguity in notes and inpatient handovers. Certainly a reduction in the volume of paper documentation required of physicians might reduce the temptation to abbreviate excessively in notes. During handovers, the use of standard handover templates or templates for providing instructions to patients may decrease the use of abbreviations and lessen the risk of ambiguity. In addition, increasing the time allotted for verbal communication in handovers between providers across different settings of care, and for interacting with patients to provide instructions, with an opportunity for asking questions, may be beneficial.

Further information about the risks of error and patient harm that can result from ambiguous abbreviations may expedite the development of policies and technological innovations to address this problem. In the meantime, Sheppard and colleagues have provided a wake-up call to healthcare providers everywhere to think twice about how excessive use of abbreviations in clinical notes may adversely impact the care of patients.

Funding: Dr Walsh was supported by a Robert Wood Johnson Physician Faculty Scholar award.

Competing interests: None.
Arch Dis Child 2008;93:816-817. doi:10.1136/adc.2008.141473

\section{REFERENCES}

1. Sheppard JE, Weidner LCE, Zakai S, et al. Ambiguous abbreviations: an audit of abbreviations in paediatric note keeping. Arch Dis Child 2008;93:204-6.

2. Kaushal R, Bates DW, Landrigan C, et al. Medication errors and adverse drug events in pediatric inpatients. JAMA 2001;285(16):2114-20.

3. Fortescue EB, Kaushal R, Goldman DA, et al. Prioritizing strategies for preventing medication errors and adverse drug events in pediatric inpatients. Pediatrics 2003;111:722-9.

4. The Institute for Safe Medication Practices. Please don't sleep through this wake up call. ISMP Medication Safety Alert!, May 2, 2001. Available from http://www.ismp.org/newsletters/acutecare/articles/ 20010502.asp (accessed 16 July 2008).

5. National Patient Safety Goals. 2008 National Patient Safety Goals. Hospital program. Available from http://www.jointcommission.org/PatientSafety/ NationalPatientSafetyGoals/08_hap_npsgs.htm (accessed 16 July 2008).

6. Bates DW, Cullen DJ, Laird N, et al. Incidence of adverse drug events and potential adverse drug events: implications for prevention. JAMA 1995;274(1):29-34.

7. Walsh KE, Landrigan CP, Adams WG, et al. Effect of computer order entry on prevention of serious medication errors in hospitalized children. Pediatrics 2008;121:e421-7.

8. Hartzband $\mathbf{P}$, Groopman J. Off the record--avoiding the pitfalls of going electronic. $N$ Engl J Med 2008;358:1656-8.

9. NHS connecting for health. http://www. connectingforhealth.nhs.uk. (accessed 16 July 2008).

\section{Cystic fibrosis and the transition to adult health services}

\section{Simon C Langton Hewer, ${ }^{1}$ Jennifer Tyrrell ${ }^{2}$}

There is no other condition quite like cystic fibrosis (CF). Faulty genes that the parents usually did not know they carried have caused it. The newborn baby will usually be free of any problems, but the young child is likely to have problems with weight gain and with frequent respiratory infections. Once the diagnosis has been made, the family must learn a complex new set of rules: medication needs to be given several times every day, and chest physiotherapy must be learned and performed twice a day,

\footnotetext{
${ }^{1}$ Department of CF and Respiratory Medicine, Bristol Royal Hospital for Children, Bristol, UK; ${ }^{2}$ Department of Paediatrics, Royal United Hospital, Bath, UK

Correspondence to: Dr S C Langton Hewer, Department of CF and Respiratory Medicine, Bristol Royal Hospital for Children, Upper Maudlin Street, Bristol BS2 8NB, UK; simon.langtonhewer@bris.ac.uk
}

sometimes more. The family and later the child need to become medical experts: they will need to recognise when they need to seek extra help from their CF team-how do they know when the child is coughing enough to need another appointment? They will need to learn to work with a whole range of willing and enthusiastic practitioners including doctors, nurses, physiotherapists, dieticians, psychologists, social workers and pharmacists. Not to mention the additional worries of school absences for inpatient and outpatient consultations. Then on top of that there are the family crisesnot just the normal ones that all families will go through, but those when the child may grow Pseudomonas aeruginosa for the first time and a 2-week hospital admission is required, often with minimal advance notice. As the child grows up, they will be expected to learn more about their health and how to maintain it, with a gradual reduction in responsibility from their parents and the expectation that they will become largely independent of parental input.

There is convincing evidence in favour of improving survival for patients with CF, despite the fact that there is as yet no definitive treatment to cure the defect at a cellular level. ${ }^{12}$ This improved survival is a reflection in part of the improving and pro-active care provided during childhood. Continuous improvements in health and survival suggest that mean survival of recently born infants may be greater than 50 years (fig 1). ${ }^{2}$ New treatments are being developed that are expected to modify the course of the disease and further improve survival. The CF community eagerly awaits the results from these studies. Both paediatric and adult care is likely to become even more proactive with improving health surveillance and aggressive early management of complications. This should lead to further improvements in CF survival. 